\title{
"Knowledge And Attitude on Self Monitoring of Blood Glucose (Smbg) Among Diabetic Patients Belongs to Waghodia Taluka"
}

\author{
Mr.Ravindra Hnhod ${ }^{1}$, Mr. Kevin S. Christian ${ }^{2,}$ Ms.Pooja.G ${ }^{3}$, Mr.Prem.R ${ }^{4,}$ \\ Ms.Priyal. ${ }^{5,}$ Mr.Rajat.A ${ }^{6,}$ Ms.Riya.R ${ }^{7}$ \\ ${ }^{I}$ Department Of MSN Nursing Sumandeep Nursing College Piparia, Waghodia, Vadodara \\ ${ }^{2}$ Assistant Professor Department Of Medical Surgical Nursing, Sumandeep Nursing College, Piparia, \\ Vadodara. \\ ${ }^{3}$ Final Year B.Sc. Nursing Student Sumandeep Nursing College Piparia, Waghodia, Vadodara \\ ${ }^{4}$ Final Year B.Sc. Nursing Student Sumandeep Nursing College Piparia, Waghodia, Vadodara \\ ${ }^{5}$ Final Year B.Sc. Nursing Student Sumandeep Nursing College Piparia, Waghodia, Vadodara \\ ${ }^{6}$ Final Year B.Sc. Nursing Student Sumandeep Nursing College Piparia, Waghodia, Vadodara \\ ${ }^{7}$ Final Year B.Sc. Nursing Student Sumandeep Nursing College Piparia, Waghodia, Vadodara
}

\begin{abstract}
:
Background: Self-monitoring of blood glucose (SMBG) has been accepted as an important instrument that empowers people with diabetes to achieve and maintain therapeutic goalsThis study is

Aims \&Objective: 1] To assess the level of knowledge on self-monitoring of blood glucose (SMBG) among of diabetic patients. 2] Assess the Attitude on self-monitoring of blood glucose (SMBG) among of diabetic patients. 3] Find out the Correlation between level of Knowledge and Attitude on self-monitoring of blood glucose (SMBG) among diabetic patients. 4] Find out the association between levels of knowledge with selected demographic variables of diabetes mellitus patients. 5] Find out the association between attitudes with selected demographic variables of diabetes mellitus patients in WaghodiaTaluka.

Methods: The interventional study was conducted \&sample consisted of 200 patients of selected area of WaghodiaTaluka.The tools used for data collection was a set demographic variables. Interview scale will be used to assess the knowledge \&Likert scale will be used to assess the Attitude on SMBG. A planned teaching program on knowledge and attitude on SMBG among diabetic patients belongs to waghodiataluka was the intervention of the study. Content validity of the tool was ensured by verifying it with experts from the field of medicine and nursing.In the data gathering process, a pre-test was administered to assess the knowledge level of sample on the same day was conducted. After $7^{\text {th }}$ day post test was administered using the same set of questionnaire to assess the knowledge.

Interpretation: The result showed that negative correlation between knowledge and attitude on SMBG in among diabetic patient belong to WaghodiaTaluka.

Conclusion: The motivated the diabetic patient about knowledge and attitude on SMBG in diabetic patient. It has given a new avenue to the researcher to widen the horizon on move research aspect of knowledge and attitude on $S M B G$ in diabetic patient.
\end{abstract}

Keywords: Assess, Effectiveness, Knowledge and attitude, SMBG, DM patient,

\section{Introduction}

Diabetes mellitus is a chronic multi system disease related to the abnormal insulin production, impaired utilization of insulin or both. Diabetes mellitus is a serious health problem in the world and its prevalence is increasing rapidly.Self-monitoring of blood glucose (SMBG) has been accepted as an important instrument that empowers people with diabetes to achieve and maintain therapeutic goals. The WHO estimates 177 million people with diabetes worldwide. In India, there are nearly 35 million diabetic patients and the number would go unto 80 million by 2030. If unchecked the diabetes can cause disease related to kidney, heart and nerve system at later stage.

\section{Need For Study}

The WHO estimated 30 million people worldwide had diabetes mellitus in 1985. A decade later, the global burden of diabetes mellitus was estimated to be 135 million. In the year 2006 it was 246 million. This is likely to increase at least 366 million by 2030 . Around 3.2 million deaths every year are attributable to complications of diabetes; six deaths every minute. The top 10 countries, in numbers of sufferers are India, China, USA, Indonesia, Japan, Pakistan, Russia, Brazil, Italy, and Bangladesh. At present in India 41 million patients suffering with diabetes mellitus and this number will reach 79.4 million by 2030 . 
"Knowledge And Attitude On Self Monitoring Of Blood Glucose (Smbg) Amon...

Objectives Of The Study

\section{Statement Of The Study}

1) To assess the level of knowledge on self-monitoring of blood glucose (SMBG) among of diabetic patients of WaghodiaTaluka.

2) Assess the Attitude on self-monitoring of blood glucose (SMBG) among of diabetic patients of WaghodiaTaluka.

3) Find out the Correlation between level of Knowledge and Attitude on self-monitoring of blood glucose (SMBG) among diabetic patients belongs to WaghodiaTaluka.

4) Find out the association between levels of knowledge with selected demographic variables of diabetes mellitus patients in WaghodiaTaluka.

5) Find out the association between attitudes with selected demographic variables of diabetes mellitus patients in WaghodiaTaluka.

\section{Hypothesis}

$\Rightarrow \mathbf{H}_{1}$ : There was significant association between existing level of knowledge score on SMBG with their socio-demographic variables

$\Rightarrow \mathbf{H}_{2}$ : There was significant correlation between Knowledge and Attitude score on SMBG.

\section{Assumptions}

- Community people may have limited knowledge on SMBG.

- DM patients may have positive or negative attitude on SMBG.

\section{Operational Definition}

$\Rightarrow$ Knowledge: It refers to level of understanding regarding self-monitoring of blood glucose (SMBG) among diabetic patients belongs to waghodiataluka.

$\Rightarrow$ Attitude: It is considered predisposition or a tendency to respond positively or negatively towards SMBG by diabetes mellitus patients.

$\Rightarrow$ SMBG: Self-monitoring of blood glucose is a blood test monitor by self with a specialized device.

$\Rightarrow$ Diabetes patients: Person suffering from diabetes mellitus type2 regarding at geographical area of waghodiataluka.

\section{Research Methodology}

Methodology of research indicates the general pattern of organizing the procedure for the empirical study together with the method of obtaining valid and reliable data for problem under investigation.

Research Approach:-A Quantitative Research Approach Is Adopted For The Study.

Research Design:-Non Experimental Descriptive Design

Research Variables

Dependent variable

$\Rightarrow$ Knowledge on SMBG of patients with diabetes mellitus.

$\Rightarrow$ Attitude onSMBG of patients with diabetes mellitus.

\section{Socio-Demographic variable}

Age, gender, marital status, education qualification, occupational status, monthly income demographic area, BMI, duration of the DM, previous source of health information, family history, abdominal girth.

SETTING OF THE STUDY: The study will be conducted in the rural area of Waghodiataluka.

Target Population: Diabetic Patients.

Sample Size: 209 Diabetic Patients. $(\mathrm{N}=209)$

Sampling Technique: Non Probability Convenient Sampling

\section{Method Of Data Collection}

Self-Structured \& Administered Interview Scale And Self Modified Likert Scale

\section{Sampling Criteria}

Sampling criteria is the list of characteristics essential for inclusion or exclusion in the target population. 


\section{Inclusion Criteria}

1. Diabetic Patients from a Waghodiataluka.

2. Those who are willing to participate in the study.

3. Those who know Gujarati, Hindi or English Language.

\section{Exclusion Criteria}

1. The Diabetic Patients who are not available at the time of data Collection.

2. The Diabetic Patients who are not willing to participate in the Study.

\section{Pilot Study}

Small scale version or a trial run done in preparation for a major study. The tool was used for pilot study to test feasibility and practicability. 20 Diabetic Patients were selected from the Piparia village Vadodara. The convenient sampling technique was used to select samples. The findings showed that the study is feasible and practical.

\section{Development And Description Of Tool}

An instrument selected in a research should be as far as possible, the vehicle that would best obtain data for drawing conclusion, which were pertinent to the study.

$\Rightarrow$ Section A Socio demographic variables: Age in years, gender, marital status, educational qualification, occupational status, monthly income of family (rupees), family history of diabetes, duration of diabetes mellitus in years, and previous sources of health information

$\Rightarrow$ Section B Knowledge interview scale: This section consists of 15 statements to assess the level of Knowledge self-monitoring of blood glucose (SMBG) among diabetic patients.

- Inadequate knowledge: score less than $50 \%$

- Moderately adequate knowledge: score $50 \%-75 \%$

- Adequate knowledge: score more than $75 \%$

$\Rightarrow$ Section C Attitude Scale: This section consist of 10 items to assess the Attitude on self-monitoring of blood glucose (SMBG) using 3 point likert scale such as "Strongly Agree", "Agree", "Disagree". The maximum score is 30 .

\section{Result}

Table 1:frequency and percentage distribution of diabetic patient according to demographic variables $\mathbf{N}=\mathbf{2 0 9}$

\begin{tabular}{|c|c|c|c|c|}
\hline $\begin{array}{l}\text { Sr. } \\
\text { no }\end{array}$ & Demographic variables & Characteristics & Frequency & $\begin{array}{c}\text { Percentage } \\
(\%)\end{array}$ \\
\hline \multirow{4}{*}{1} & \multirow{4}{*}{ Age in years } & $30-40$ years & 22 & 10.5 \\
\hline & & 41-50 years & 43 & 20.6 \\
\hline & & $51-60$ years & 123 & 58.9 \\
\hline & & 60 and above & 21 & 10.0 \\
\hline \multirow{2}{*}{2} & \multirow{2}{*}{ Gender } & Male & 127 & 60.8 \\
\hline & & Female & 82 & 39.2 \\
\hline \multirow{4}{*}{3} & \multirow{4}{*}{ Marital status } & Single & 200 & 95.7 \\
\hline & & Married & 2 & 1.0 \\
\hline & & Divorced & 7 & 3.3 \\
\hline & & Separated/widowed & 00 & 00 \\
\hline \multirow{4}{*}{4} & \multirow{4}{*}{ Educational Qualification } & Illiterate & 43 & 20.6 \\
\hline & & Primary & 88 & 42.1 \\
\hline & & Higher Secondary & 62 & 29.7 \\
\hline & & Graduate $\&$ above & 16 & 7.7 \\
\hline \multirow{5}{*}{5} & \multirow{5}{*}{ Occupational Status } & Private employee & 133 & 63.6 \\
\hline & & Business & 49 & 23.4 \\
\hline & & Government employee & 6 & 2.9 \\
\hline & & Self-employee & 21 & 10.0 \\
\hline & & Retired & 00 & 00 \\
\hline \multirow{4}{*}{6} & \multirow{4}{*}{$\begin{array}{l}\text { Monthly Income of Family } \\
\text { (Rupees) }\end{array}$} & $2500-5000$ & 49 & 23.4 \\
\hline & & $5001-10000$ & 130 & 62.2 \\
\hline & & $10001-20000$ & 24 & 11.5 \\
\hline & & 20000 and above & 6 & 2.9 \\
\hline \multirow{2}{*}{7} & \multirow{2}{*}{ Family History of diabetes } & Present & 19 & 9.1 \\
\hline & & Not Present & 190 & 90.9 \\
\hline \multirow{3}{*}{8} & \multirow{3}{*}{$\begin{array}{l}\text { Duration of diabetes } \\
\text { mellitus in years }\end{array}$} & $0-5$ years & 164 & 78.5 \\
\hline & & $5-10$ years & 34 & 16.3 \\
\hline & & $10-15$ years & 8 & 3.8 \\
\hline
\end{tabular}


"Knowledge And Attitude On Self Monitoring Of Blood Glucose (Smbg) Amon...

\begin{tabular}{|c|c|c|c|c|} 
& & 15 years \& above & 3 & 1.4 \\
\hline \multirow{4}{*}{9} & \multirow{3}{*}{$\begin{array}{c}\text { Previous sources of health } \\
\text { information }\end{array}$} & TV/Radio/ Posters & 00 & 00 \\
\cline { 3 - 4 } & & Friends & 00 & 00 \\
\cline { 3 - 4 } & & Health personal & 170 & 81.3 \\
\cline { 3 - 4 } & & Family members & 39 & 18.7 \\
\hline
\end{tabular}

\section{Analysis Of Knowledge And Attitude}

A) Assessment of knowledge on self-monitoring of blood glucose (SMBG) among diabetic patients

Table 2: Mean, SD, and mean\% score for the test knowledge level

\begin{tabular}{|c|c|c|c|c|}
\hline SCALE & MAX SCORE & MEAN & SD & MEAN\% \\
\hline KNOWLEDGE & 15 & 10.10 & 2.07 & $67.33 \%$ \\
\hline
\end{tabular}

Table 2: illustrates that overall knowledge score was found to have a mean of 10.10, standard deviation of 2.07 and mean\% of $67.33 \%$.

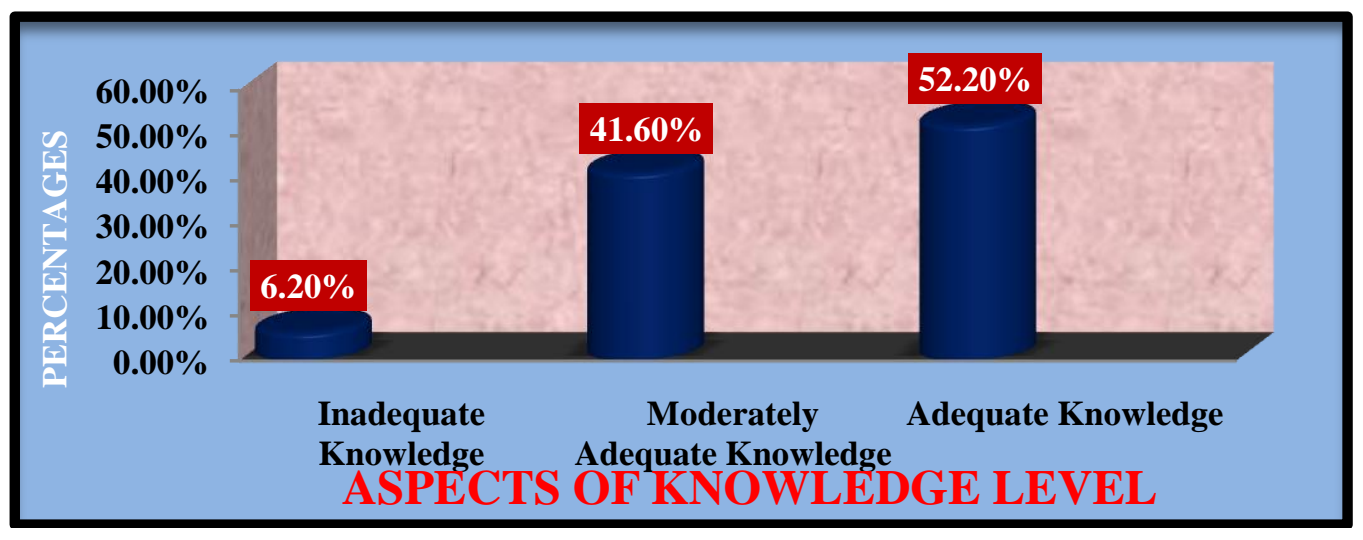

Figure 1: Bar graph represents that $52.2 \%$ is having adequate knowledge, $41.6 \%$ is having moderately adequate knowledge and $6.2 \%$ having inadequate knowledge.

B) Assessment of Attitude on self-monitoring of blood glucose (SMBG) among diabetic patients

Table 3: Mean, SD and mean $\%$ of attitude scale

\begin{tabular}{|c|c|c|c|c|}
\hline SCALE & MAX SCORE & MEAN & SD & MEAN\% \\
\hline ATTITUDE & 30 & 18.35 & 2.77 & 61.16 \\
\hline
\end{tabular}

Table 3:illustrates that overall attitude score was found to have a mean of 18.35, standard deviation of 2.77 and mean $\%$ of $61.16 \%$.

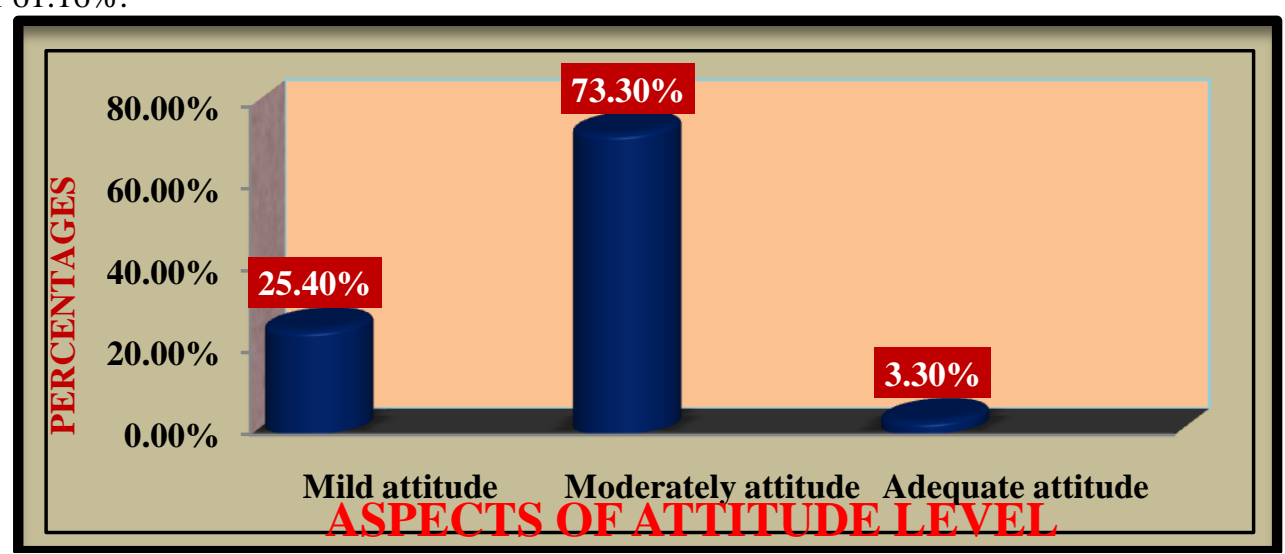

Figure 2: Bar graph representsthat majority $73.3 \% \%$ is having moderately attitude, $25.4 \%$ is having mild attitude and 3.3\% having adequate attitude. 
"Knowledge And Attitude On Self Monitoring Of Blood Glucose (Smbg) Amon...

Table 4: relationship between knowledge and attitude on self-monitoring of blood glucose (smbg) among diabetic patients

\begin{tabular}{|c|c|c|c|c|c|c|}
\hline & Items & Mean & Mean\% & SD & $\begin{array}{c}\text { Correlation between } \\
\text { knowledge and attitude }\end{array}$ & REMARKS \\
\hline Knowledge & 15 & 10.10 & $67.33 \%$ & 2.07 & -0.153 & $\begin{array}{c}\text { Negative } \\
\text { Correlation }\end{array}$ \\
\hline Attitude & 30 & 18.35 & $61.16 \%$ & 2.77 & & \\
\hline
\end{tabular}

Table 4: illustrates that the correlation between knowledge and attitude is $r=-0.153$ is found moderate negative correlation.

Table 5: Association of socio demographic variables with knowledge

\begin{tabular}{|c|c|c|c|c|c|c|c|c|}
\hline Sno & Variables & IA & MA & $\mathbf{A}$ & Total & $\mathbf{X}^{2}$ & Df & $\begin{array}{c}\text { Level Of } \\
\text { Significance }\end{array}$ \\
\hline 1 & Age (In Years) & & & & & & & \\
\hline & $30-40$ years & 5 & 17 & 0 & 22 & \multirow{4}{*}{3.80} & \multirow{4}{*}{6} & \multirow{4}{*}{$(3.80<12.59) \mathrm{NS}$} \\
\hline & $41-50$ years & 11 & 30 & 2 & 43 & & & \\
\hline & 51-60 years & 29 & 89 & 5 & 123 & & & \\
\hline & 60 and above & 8 & 13 & 0 & 21 & & & \\
\hline \multirow[t]{3}{*}{2} & Gender & & & & & & & \\
\hline & Male & 33 & 90 & 4 & 127 & \multirow{2}{*}{0.09} & \multirow{2}{*}{2} & \multirow{2}{*}{$(0.09<5.99) \mathrm{NS}$} \\
\hline & Female & 20 & 59 & 3 & 82 & & & \\
\hline \multirow[t]{4}{*}{3} & Marital status & & & & & & & \\
\hline & Single & 50 & 143 & 7 & 200 & \multirow{3}{*}{2.10} & \multirow{3}{*}{4} & \multirow{3}{*}{$(2.10<9.48) \mathrm{NS}$} \\
\hline & Married & 0 & 2 & 0 & 2 & & & \\
\hline & Divorced & 3 & 4 & 0 & 7 & & & \\
\hline 4 & \multicolumn{8}{|c|}{ Educational Qualification } \\
\hline & Illiterate & 9 & 34 & 0 & 43 & \multirow{4}{*}{20.25} & \multirow{4}{*}{6} & \multirow{4}{*}{$(20.25>12.59) \mathrm{S}$} \\
\hline & Primary & 15 & 70 & 3 & 88 & & & \\
\hline & Higher Secondary & 19 & 39 & 4 & 62 & & & \\
\hline & Graduate $\&$ above & 10 & 6 & 0 & 16 & & & \\
\hline 5 & \multicolumn{8}{|l|}{ Occupational Status } \\
\hline & Private employee & 31 & 98 & 4 & 133 & \multirow{4}{*}{20.67} & \multirow{4}{*}{6} & \multirow{4}{*}{$(20.67>12.59) \mathrm{S}$} \\
\hline & Business & 16 & 32 & 1 & 49 & & & \\
\hline & $\begin{array}{c}\text { Government } \\
\text { employee }\end{array}$ & 2 & 2 & 2 & 6 & & & \\
\hline & Self-employee & 4 & 17 & 0 & 21 & & & \\
\hline 6 & \multicolumn{8}{|c|}{ Monthly Income of Family (Rupees) } \\
\hline & $2500-5000$ & 10 & 36 & 3 & 49 & \multirow{4}{*}{8.43} & \multirow{4}{*}{6} & \multirow{4}{*}{$(8.43<12.59) \mathrm{NS}$} \\
\hline & $5001-10000$ & 30 & 97 & 3 & 130 & & & \\
\hline & $10001-20000$ & 11 & 12 & 1 & 24 & & & \\
\hline & 20000 and above & 10 & 36 & 3 & 49 & & & \\
\hline 7 & \multicolumn{8}{|c|}{ Family History of diabetes } \\
\hline & Present & 4 & 15 & 0 & 19 & \multirow{2}{*}{1.02} & 2 & $(100<5$ 99)NS \\
\hline & Not Present & 49 & 134 & 7 & 190 & & 2 & $(1.02<5.99) 1 \mathrm{NS}$ \\
\hline 8 & Duration of diabetes & itus in $y$ & & & & & & \\
\hline & $0-5$ years & 37 & 121 & 6 & 164 & & & \\
\hline & $5-10$ years & 11 & 22 & 1 & 34 & 512 & 6 & $(512<1259) \mathrm{NS}$ \\
\hline & $10-15$ years & 3 & 5 & 0 & 8 & 5.12 & 0 & $(5.12<12.59) 1 \mathrm{NS}$ \\
\hline & 15 years $\&$ above & & & & & & & \\
\hline 9 & Previous sources of $h$ & $\mathrm{~h}$ inforn & & & & & & \\
\hline & Health personal & 42 & 122 & 6 & 170 & & & \\
\hline & Family members & 11 & 27 & 1 & 39 & 0.21 & 2 & - 5.99$) \mathrm{N}$ (v) \\
\hline
\end{tabular}

$\mathrm{KEY}={ }^{\mathrm{S}}$ is significant, ${ }^{\mathrm{NS}}$ is not significant. $\mathrm{DF}=$ Degree of freedom

$>\mathbf{H}_{2}$ : Therewas significant association between existing level of knowledge score on SMBG with their sociodemographic variables. So here to test the hypothesis, chi-square test has been used. Data have been analyzed with the use of SPSS version 20.0 and the outputs are depicted in the above table. The table reveals that there is no significant association between pre- test knowledge score and selected demographic variables with 0.05 level of significant except educational qualification, and occupational status of sample's $\mathrm{P}$ calculated value is greater than 0.05 level of significance

\section{Discssion \& Conclusion}

This chapter includes conclusion, implication, limitations and recommendations. The following conclusions were drawn from the finding of the present study. The research approach adopted in the present study is quantitative research approach \& design was Non Experimental Descriptive design. The motivated the diabetic patient about knowledge and attitude on SMBG in diabetic patient. It has given a new avenue to the 
researcher to widen the horizon on move research aspect of knowledge and attitude on SMBG in diabetic patient.

\section{References}

[1]. Diagnosis and classification of diabetes Mellitus. 2009 Jan 1 [cited 2016 Mar 28];32(Suppl Available from: http://www.ncbi.nlm.nih.gov/pmc/articles/PMC2613584/.

[2]. Susddarth and Brunner " Text book of medical surgical Nursing” Mew York. J.B. Lippicott company 2000.

[3]. Medscapelogin.[cited2016mar28].availablefrom:http://www.medscape.org/viewarticle/709187.

[4]. Ahmed am. History of diabetes mellitus.saudi medical journal. 2013 sep 27 2016mar25;23(4):373-8.

[5]. Ozulik f yiginer o, arsolan e, serdar ma, assoc between glycemic control and level of knowledge and awareness of type-2 diabetes, pol arch med wemn 2010; oct;120(10); 399-406.

[6]. Lippincott basic nursing research, 9 thedition, page no-910-11. 